\title{
Early autonomic dysfunction in type 1 diabetes: a reversible disorder?
}

\author{
M. Rosengård-Bärlund • L. Bernardi • J. Fagerudd • \\ M. Mäntysaari • C. G. Af Björkesten • H. Lindholm • \\ C. Forsblom • J. Wadén • P.-H. Groop • \\ FinnDiane Study Group
}

Received: 17 January 2009 /Accepted: 23 February 2009/Published online: 2 April 2009

(C) Springer-Verlag 2009

\begin{abstract}
Aims/hypothesis Cardiac autonomic neuropathy is associated with increased morbidity and mortality rates in patients with type 1 diabetes. The prevalence of early autonomic abnormalities is relatively high compared with the frequency of manifest clinical abnormalities. Thus, early autonomic dysfunction could to some extent be functional and might lead to an organic disease in a subgroup of patients only. If this is true, manoeuvres such as slow deep-breathing, which can improve baroreflex sensitivity (BRS) in normal but not in denervated hearts, could also modify autonomic modulation in patients with type 1 diabetes, despite autonomic dysfunction.
\end{abstract}

\footnotetext{
M. Rosengård-Bärlund · J. Fagerudd · C. G. Af Björkesten •

C. Forsblom · J. Wadén $\cdot$ P.-H. Groop $(\bowtie)$

Folkhälsan Research Center, Folkhälsan Institute of Genetics, Biomedicum Helsinki (C318b), University of Helsinki,

P.O. Box 63, FIN-00014 Helsinki, Finland

e-mail: per-henrik.groop@helsinki.fi

M. Rosengård-Bärlund · J. Fagerudd · C. G. Af Björkesten •

C. Forsblom · J. Wadén · P.-H. Groop

Division of Nephrology, Department of Medicine,

Helsinki University Central Hospital,

Helsinki, Finland

L. Bernardi

Department of Internal Medicine,

University of Pavia and IRCCS S Matteo,

Pavia, Italy

M. Mäntysaari

Aeromedical Centre (AMC), Centre for Military Medicine,

Helsinki, Finland

H. Lindholm

Department of Health and Work Ability,

Finnish Institute of Occupational Health,

Helsinki, Finland
}

Methods We compared 116 type 1 diabetic patients with 36 matched healthy control participants and 12 hearttransplanted participants with surgically denervated hearts. Autonomic function tests and spectral analysis of heart rate and blood pressure variability were performed. BRS was estimated by four methods during controlled (15 breaths per minute) and slow deep-breathing (six breaths per minute), and in supine and standing positions.

Results Conventional autonomic function tests were normal, but resting spectral variables and BRS were reduced during normal controlled breathing in patients with type 1 diabetes. However, slow deep-breathing improved BRS in patients with type 1 diabetes, but not in patients with surgically denervated hearts. Standing induced similar reductions in BRS in diabetic and control participants.

Conclusions/interpretation Although we found signs of increased sympathetic activity in patients with type 1 diabetes, we also observed a near normalisation of BRS with a simple functional test, indicating that early autonomic derangements are to a large extent functional and potentially correctable by appropriate interventions.

Keywords Baroreflex sensitivity - Cardiac autonomic neuropathy · Diabetic neuropathy $\cdot$ Heart rate variability . Hypertension - Type 1 diabetes mellitus

$\begin{array}{ll}\text { Abbreviations } \\ \text { ABPM } & \text { Ambulatory blood pressure measurement } \\ \text { BRS } & \text { Baroreflex sensitivity } \\ \text { CAN } & \text { Cardiac autonomic neuropathy } \\ \text { DBP } & \text { Diastolic blood pressure } \\ \text { HRV } & \text { Heart rate variability } \\ \text { SBP } & \text { Systolic blood pressure } \\ \text { SDNN } & \text { Standard deviation of all RR intervals } \\ \text { TF } & \text { Transfer function technique }\end{array}$




\section{Introduction}

Cardiac autonomic neuropathy (CAN) is a serious although poorly understood long-term diabetic complication. Importantly, diabetic patients with autonomic neuropathy have consistently been shown to carry an increased risk of premature death. A recent meta-analysis demonstrated that the presence of CAN, defined as decreased heart rate variability (HRV), doubled the relative risk of silent myocardial ischaemia and mortality [1]. Moreover, the risk of cardiovascular events is already increased due to an imbalance in the autonomic nervous system [2].

However, an unresolved problem is the mismatch between the high prevalence of autonomic abnormalities and the relatively limited number of patients who develop organic neuropathy and full-blown clinical abnormalities. This suggests that, at least at an early stage, autonomic dysfunction could to some extent be functional and might lead to organic disease in a selected number of patients only. Such a notion does not necessarily decrease the importance of detecting early autonomic disturbances, as similar prognostic values for reduced HRV and reduced baroreflex sensitivity (BRS) have been reported after myocardial infarction [3, 4], in heart failure $[5,6]$ and in hypertension [7,8], all conditions known to be dependent upon functional autonomic abnormalities.

However, if the notion turns out to be correct, it could explain why diabetic autonomic abnormalities confer an increased risk of cardiovascular mortality, regardless of a relatively lower proportion of clinically evident organic neuropathy.

A high prevalence of CAN, reduced HRV and blunted spontaneous BRS in patients with type 1 as well as in patients with type 2 diabetes have been reported previously [9-15]. It is of note that the tests used allow early detection of abnormalities in the autonomic nervous system. However, unlike in heart failure or hypertension, in patients with diabetes these abnormalities have always been interpreted as evidence of early organic neuropathy [16]. Interestingly, previous studies have shown that a simple functional manoeuvre like slow deep-breathing can increase the BRS [17-19], an important and well-established prognostic index, and also reduce the sympathetic tone in conditions like heart failure, hypertension and chronic obstructive pulmonary disease [20-22]. In contrast, the upright posture increases sympathetic activity and reduces the BRS [23].

Thus, if a functional nature of early autonomic abnormalities could be demonstrated in patients with type 1 diabetes, this would not only be of theoretical, but also of great practical importance for the management of diabetes. Previous studies have already established a positive role for physical activity and other interventions in the correction of functional autonomic abnormalities and improved survival rates in heart failure [24, 25]. However, it is still unknown whether it is possible to correct these abnormalities in patients with type 1 diabetes. Therefore, the aim of this study was to test whether autonomic abnormalities in type 1 diabetic patients may be of a functional nature. For this purpose, we tested whether it is possible to increase BRS by slow deep-breathing in a large group of patients with type 1 diabetes, in a group of participants with a heart transplant and in a group of age-matched control participants. We also tested whether an opposite stimulus, active standing, could induce similar changes in the diabetic and control participants. We reasoned that organic neuropathy would produce minor or no change in the functional tests, similar to what could be expected in the group with denervated hearts. In contrast, functional abnormalities would produce a normal or only mildly reduced response resembling that in the control group.

\section{Methods}

Study population The IDEAL Study (IDentification of EArly mechanisms in the pathogenesis of diabetic Late complications) was launched in 2003 as a sub-study to the nationwide FinnDiane Study. It is a population-based, observational follow-up study designed to identify early markers of diabetes-specific late complications. The participants were recruited through the register of the Social Insurance Institution that comprises all patients entitled to special reimbursement of insulin or glucose-lowering medication in Finland. This register covers approximately $98 \%$ of Finnish patients with type 1 diabetes [26]. Selection criteria were diabetes diagnosed before the age of 35 years, duration of diabetes of 6 to 12 years and age at the time of inclusion between 18 and 35 years. A total of 400 individuals residing in the Helsinki metropolitan area fulfilled the selection criteria and were invited. Of those invited, 165 persons responded, of whom 25 were excluded since they had other types of diabetes than type 1, were currently pregnant or failed to attend. Consequently, 140 participants were enrolled and 125 participated in all examinations at baseline. Type 1 diabetes was defined as C-peptide deficiency $(<0.03 \mathrm{nmol} / \mathrm{l})$ and initiation of permanent insulin treatment within 1 year after diagnosis of diabetes. None of the patients showed clinical signs of cardiovascular disease; six were taking antihypertensive medication (five with ACE inhibitors, one a combination of ACE inhibitor and diuretic). Our 36 age- and sex-matched healthy control participants were recruited by email advertisements among university students and staff. Only individuals with normal fasting glucose and without first- 
degree relatives with diabetes mellitus were included. A third group of heart-transplanted participants was studied retrospectively. This group comprised 12 participants (5 men, 7 women, aged $54.7 \pm 2.4$ years), who had undergone orthotopic heart transplantation $34.7 \pm 4.9$ months previously. These participants were part of a previously published study [27], documenting absent or only rudimentary renervation. As the protocol of that study also contained similar recordings (not used in the previous publication) to those for our patients with type 1 diabetes, they were included in the present study to test whether and to what extent an almost denervated heart could respond to interventions capable of increasing BRS. Before participation, all participants gave their written informed consent. The study protocols were approved by the Ethics Committee of Helsinki University Hospital and by the Ethics Committee of the University of Pavia, Italy (for hearttransplanted participants).

Protocol During two visits, the type 1 diabetic and control participants underwent a clinical examination, resting ECG, laboratory testing, one $24 \mathrm{~h}$ and two overnight urine collections, ambulatory blood pressure measurement (ABPM) and testing of the autonomic nervous system. Each patient completed a detailed questionnaire on life style, smoking habits and family history.

Autonomic testing All participants were investigated in a quiet room, at a temperature between $19^{\circ} \mathrm{C}$ and $23^{\circ} \mathrm{C}$, between 08:00 and 14:00 hours. Before the examination, the participants were asked to abstain from alcohol for $36 \mathrm{~h}$, and from caffeinated beverages and cigarettes for $12 \mathrm{~h}$. A light meal was permitted $2 \mathrm{~h}$ before testing. ECG was recorded using a bipolar precordial lead. Continuous blood pressure was monitored with a digital plethysmograph (Finapres 2300; Ohmeda, Louisville, CO, USA) from the middle finger of the right arm held at heart level. Recorded signals were digitised with a 12 bit resolution at a sampling rate of $200 \mathrm{~Hz}$ using a data acquisition system (WinAcq; Absolute Aliens, Turku, Finland).

The participants underwent a set of four cardiovascular autonomic function tests: (1) the expiration:inspiration ratio of RR interval during slow deep-breathing; (2) the maximum:minimum 30:15 ratio of RR interval during active standing; (3) the systolic blood pressure (SBP) response to standing; and (4) the maximum:minimum ratio of RR interval during a Valsalva manoeuvre. In line with current recommendations, CAN was defined as the presence of two or more abnormal tests [28, 29]. Due to technical artefacts or ectopic beats during recording or a hypoglycaemic episode during the preceding $24 \mathrm{~h}$, nine participants were excluded from the analyses of HRV and blood pressure variability.
Recording for spectral analysis of HRV and BRS ECG and continuous blood pressure were recorded in the supine position during $5 \mathrm{~min}$ controlled breathing at a frequency similar to that of spontaneous breathing (15 breaths per minute). Previous studies [30] have shown that this procedure, if properly performed, does not induce major modifications in the autonomic tone, yet allows correct analysis of HRV by removing artefact effects of irregular respiration into the low-frequency band [31]. Subsequently, participants were asked to take deep breaths at a fixed frequency of six breaths per minute for $1 \mathrm{~min}$. In the diabetic and control groups recordings were also taken for $5 \mathrm{~min}$ in the supine and active standing states, during spontaneous breathing.

Data analysis From the original data the time series of RR interval and SBP were obtained and power spectral analysis was performed, based on Fast Fourier transformation, allowing us to obtain the power in the low-frequency $(0.04-0.15 \mathrm{~Hz})$ and high-frequency bands $(0.15-0.40 \mathrm{~Hz})$, and the low:high frequency ratio for the RR interval. Normalised units of the low- and high-frequency bands were calculated as follows: $\mathrm{nLF}=\mathrm{LF}$ power/ $(\mathrm{LF}+\mathrm{HF}$ powers $) ; n H F=H F$ power/(LF + HF powers $)$, where $n$ stands for normalised, and HF and LF stand for high- and low-frequency, respectively. In addition, the standard deviation of all RR intervals (SDNN) was considered an index of global RR interval variability. For SBP variability we also considered the power in the low- and highfrequency bands [32].

Assessment of BRS Previous studies have shown a poor correlation between different indices of BRS, while, on the other hand, no method has shown clear superior performance over the other [33]. Accordingly, we used a set of different tests; and although we present the results of the individual methods, we also analysed BRS as the average of all methods.

BRS was determined from spontaneous fluctuations in the RR interval and SBP during the 15 and 6 breaths per minute recordings using the sequence method (BRS $+/+$, BRS-/-) [34], the alpha coefficient (Alpha low-frequency BRS) [35] and the transfer function technique (TF-BRS) [36]. In the sequence method, BRS was estimated by identifying spontaneously occurring sequences of three or more consecutive heartbeats in which both SBP and the subsequent RR intervals changed in the same direction. The minimum criteria for change were $1 \mathrm{mmHg}$ for SBP and $5 \mathrm{~ms}$ for the RR intervals. For identified up-up $(+/+)$ and down-down (-/-) sequences with a correlation coefficient between the RR intervals and the SBP in excess of 0.85 , the regression slopes (slope of the regression line between SBP and RR intervals) were calculated and the average was 
taken as a measure of $\mathrm{BRS}+/+$ and BRS-/-, respectively. The alpha coefficient (Alpha low-frequency-BRS) was calculated as the square root of the ratio of the spectral powers of RR intervals and SBP in the low-frequency range $(0.04-0.15 \mathrm{~Hz})$ when coherence was greater than 0.5 and the phase difference between SBP and RR intervals was negative. In the TF-BRS method, BRS was calculated as the average value of SBP-RR cross-spectrum divided by the SBP spectrum in the low-frequency range $(0.04-0.15 \mathrm{~Hz})$, when coherence exceeded 0.5 .

Ambulatory blood pressure measurements ABPM was performed in a subset of participants (99 patients, 29 healthy control participants) with a monitoring device (SpaceLab 90207; Spacelabs, Redmond, WA, USA). Measurements were taken at the non-dominant arm every 20 min during the day (07:00-23:00 hours) and every $60 \mathrm{~min}$ at night (23:00-07:00 hours). For analysis, day and night-time periods were defined according to the individual sleeping time. Participants with a nocturnal decrease in SBP or diastolic blood pressure (DBP) of less than $10 \%$ of the corresponding daytime value were defined as non-dippers.

Laboratory tests Venous blood samples were obtained after a light breakfast and were analysed for $\mathrm{HbA}_{\mathrm{lc}}$, lipids and serum creatinine. $\mathrm{HbA}_{\mathrm{lc}}$ concentrations were determined by an immunoturbidimetric immunoassay (Medix Biochemica, Kauniainen, Finland). Serum lipids (cholesterol, triacylglycerol, HDL-cholesterol) and creatinine were measured by enzymatic methods. Urinary AER was measured from three consecutive timed urine collections, one $24 \mathrm{~h}$ and two overnight collections. Normal AER was defined as an AER persistently $<20 \mu \mathrm{g} / \mathrm{min}$ or $<30 \mathrm{mg} / 24 \mathrm{~h}$, microalbuminuria as an $\mathrm{AER} \geq 20<200 \mu \mathrm{g} / \mathrm{min}$ or $\geq 30<300 \mathrm{mg} / 24 \mathrm{~h}$ and macroalbuminuria as an AER $\geq 200 \mu \mathrm{g} / \mathrm{min}$ or $\geq 300 \mathrm{mg} /$ $24 \mathrm{~h}$ in at least two of three urine collections [37].

Statistical analyses All analyses were performed using SPSS 16.0 for Windows (SPSS, Chicago, IL, USA). All data are presented as mean \pm SEM. Power variables were used for statistical analysis only after logarithmic transformation $\left(\log _{10}\right)$, whereas global HRV was assessed using the $\mathrm{SD}$ of the RR interval, as this variable has a more normal distribution than other indices of variability (e.g. variance).

A test of consistency of the BRS measures was carried out using Cronbach's alpha and Intraclass correlation coefficient $[33,38,39]$. A coefficient $>0.90$ was regarded as evidence of satisfactory agreement between methods [39].

Statistical differences between groups (patients with type 1 diabetes and healthy control participants) and interventions (six breaths per minute vs 15 breaths per minute controlled breathing; supine vs standing) were tested by mixed-design two-level ANOVA (repeated measures to test for the effect of breathing rate, factorial design to test between type 1 diabetic and control participants). Due to the markedly different values seen in the heart-transplanted participants as compared with the other groups, only differences between 15 and six breaths per minute were tested (paired $t$ tests). Other differences between type 1 diabetic and control participants were analysed with $\chi^{2}$ test (for qualitative variables) or unpaired Student's $t$ test (for quantitative variables). Analysis of covariance was used to adjust for age and sex. Pearson's correlation coefficients were used to evaluate associations. Statistical significance was defined as a $p$ value of $\leq 0.05$.

\section{Results}

Clinical characteristics Clinical characteristics and laboratory results are given in Table 1 . Patients with type 1 diabetes had significantly higher SBP than the control participants. Antihypertensive medication was being taken by $6 \%$ of the diabetic patients and none of the control participants. The serum lipid concentrations were equal except for LDL-cholesterol, which was higher in type 1 diabetic patients. These also had higher estimated GFR, but there was no difference in urinary AER between the two groups.

Ambulatory blood pressure ABPM revealed a small, yet significant difference in blood pressures between the groups (Table 2). Notably, heart rate was consistently higher in the type 1 diabetic patients. The proportion of non-dippers was equal in both groups and there was no difference between the groups regarding night:day ratios of SBP, DBP, pulse pressure, mean arterial pressure or heart rate (data not shown).

Autonomic function tests One participant in each group fulfilled the diagnostic criteria for CAN. The average values of the four cardiovascular reflex tests were not significantly different in patients with type 1 diabetes compared with the control participants (Table 2).

Spectral analysis and assessment of BRS During controlled breathing at the normal rate, diabetic patients showed reduced power (in absolute value and percent) in the respiratory high-frequency band, as evidence of reduced respiratory sinus arrhythmia (Table 3). As a consequence, they also showed a higher percentage of low-frequency components and a significantly higher low-frequency:highfrequency ratio. Similarly, the power in the low-frequency band of SBP tended to be higher in type 1 diabetic patients, 
Table 1 Clinical characteristics and laboratory measurements of patients with type 1 diabetes and healthy control participants

Data are mean \pm SEM or median (range)

\begin{tabular}{|c|c|c|c|}
\hline Characteristic & Patients with type 1 diabetes & Control participants & $p$ value \\
\hline$n$ & 116 & 36 & \\
\hline Sex (men/women) & $62 / 54$ & $17 / 19$ & NS \\
\hline Age (years) & $26.3 \pm 5.7$ & $27.6 \pm 4.2$ & NS \\
\hline Duration of diabetes (years) & $8.9 \pm 1.6$ & - & - \\
\hline Age at onset (years) & $17.4 \pm 6.0$ & - & - \\
\hline BMI $\left(\mathrm{kg} / \mathrm{m}^{2}\right)$ & $24.7 \pm 4.0$ & $24.4 \pm 3.3$ & NS \\
\hline WHR & $0.86 \pm 0.07$ & $0.85 \pm 0.07$ & NS \\
\hline Current smokers $(\%)$ & 21.6 & 16.7 & NS \\
\hline Antihypertensive treatment $(\%)$ & 5.2 & 0.0 & NS \\
\hline Laser-treated retinopathy (\%) & 0.9 & 0.0 & NS \\
\hline Microalbuminuria $(n)$ & 3 & 0 & NS \\
\hline Macroalbuminuria $(n)$ & 1 & 0 & NS \\
\hline $\mathrm{HbA}_{1 \mathrm{c}}(\%)$ & $7.6 \pm 1.1$ & $5.2 \pm 0.2$ & $<0.001$ \\
\hline Total cholesterol (mmol/l) & $4.6 \pm 0.9$ & $4.4 \pm 0.9$ & NS \\
\hline HDL-cholesterol (mmol/l) & $1.7 \pm 0.5$ & $1.8 \pm 0.5$ & NS \\
\hline LDL-cholesterol (mmol/l) & $2.4 \pm 0.8$ & $2.0 \pm 0.7$ & 0.040 \\
\hline Triacylglycerol (mmol/l) & $0.97(0.43-5.03)$ & $0.87(0.49-10.68)$ & NS \\
\hline Urinary AER (mg/24 h) & $3.4(0.4-119.6)$ & $3.8(1.4-33.2)$ & NS \\
\hline Serum creatinine $(\mu \mathrm{mol} / \mathrm{l})$ & $70 \pm 11$ & $74 \pm 11$ & NS \\
\hline Estimated GFR $\left(\mathrm{ml} \mathrm{min}{ }^{-1} 1.73 \mathrm{~m}^{-2}\right)$ & $114 \pm 21$ & $103 \pm 17$ & 0.01 \\
\hline Office SBP (mmHg) & $132 \pm 13$ & $122 \pm 13$ & $<0.001$ \\
\hline Office DBP (mmHg) & $78 \pm 8$ & $75 \pm 7$ & NS \\
\hline
\end{tabular}

although the difference did not reach statistical significance. Additionally, patients with diabetes showed reduced global HRV as evidenced by reduced SDNN. With slower breathing, there was a significant increase in SDNN and also an increase in the low-frequency band, due to the fact that respiration modulated the RR interval at this frequency.

Individual measures of BRS showed reduced values in patients with type 1 diabetes as compared with the control participants at 15 breaths per minute of controlled breathing (Table 4). However, slow breathing induced a general increase in both groups, with values obtained in type 1 diabetic patients similar to those obtained in control participants at normal breathing rate $(15 / \mathrm{min})$. Individual measures of BRS showed poor reciprocal correlation (from $r=0.405$ for TF-BRS and BRS-/- during controlled breathing to $r=0.945$ for TF-BRS and Alpha lowfrequency BRS during slow deep-breathing). The average BRS from the four different methods was significantly reduced $(p<0.001)$ in diabetic patients during controlled breathing at normal breathing rate (Fig. 1). Again, slow breathing increased BRS in both groups, although the magnitude of the increase was lower in patients with type 1
Table 2 Ambulatory blood pressure and autonomic function tests in patients with type 1 diabetes and healthy control participants

Data are mean \pm SEM

$p$ values are adjusted for age and sex

$E: I$ ratio, the expiration:inspiration ratio of RR interval during slow deep-breathing; 30:15 ratio, the maximum:minimum 30/15 ratio of RR interval during active standing

\begin{tabular}{lccl}
\hline Variable & Type 1 diabetic patients & Control participants & $p$ value \\
\hline ABPM & & & \\
24 h SBP & $123 \pm 7$ & $119 \pm 8$ & 0.010 \\
24 h DBP & $73 \pm 6$ & $70 \pm 6$ & 0.007 \\
24 h mean arterial pressure & $90 \pm 6$ & $87 \pm 5$ & 0.012 \\
24 h pulse pressure & $50 \pm 5$ & $49 \pm 7$ & $\mathrm{NS}$ \\
24 h heart rate & $73 \pm 10$ & $69 \pm 8$ & 0.012 \\
Autonomic function tests & & & \\
E:I ratio & $1.40 \pm 0.01$ & $1.40 \pm 0.03$ & $\mathrm{NS}$ \\
$30: 15$ ratio & $1.67 \pm 0.03$ & $1.65 \pm 0.03$ & $\mathrm{NS}$ \\
$\Delta$ SBP for standing up $(3 \mathrm{~min})$ & $5.0 \pm 0.7$ & $3.0 \pm 1.4$ & 0.046 \\
Valsalva ratio & $2.02 \pm 0.04$ & $1.87 \pm 0.06$ & $\mathrm{NS}$ \\
\hline
\end{tabular}


Table 3 Heart rate variability and spectral analysis of RR interval and SBP during controlled and deep-breathing in patients with type 1 diabetes and healthy control participants

\begin{tabular}{|c|c|c|c|c|c|c|}
\hline \multirow[t]{2}{*}{ Variable } & \multicolumn{3}{|c|}{ Type 1 diabetic patients, $n=116$} & \multicolumn{3}{|c|}{ Healthy control participants, $n=36$} \\
\hline & Controlled $^{\mathrm{a}}$ & Deep-breathing ${ }^{\mathrm{b}}$ & $p$ value & Controlled $^{\mathrm{a}}$ & Deep-breathing ${ }^{\mathrm{b}}$ & $p$ value \\
\hline \multicolumn{7}{|l|}{ Heart rate variability } \\
\hline SDNN & $42.6 \pm 1.7 *$ & $104.6 \pm 3.5$ & $<0.001$ & $50.2 \pm 4.6$ & $110.0 \pm 7.1$ & $<0.001$ \\
\hline RMSSD & $42.3 \pm 2.2 \dagger$ & $71.3 \pm 3.2$ & $<0.001$ & $56.3 \pm 6.7$ & $77.7 \pm 6.7$ & $<0.001$ \\
\hline Log RRI LF $\left(\log \mathrm{ms}^{2}\right)$ & $2.41 \pm 0.04$ & $3.79 \pm 0.04$ & $<0.001$ & $2.38 \pm 0.08$ & $3.85 \pm 0.06$ & 0.009 \\
\hline Log RRI HF $\left(\log \mathrm{ms}^{2}\right)$ & $2.66 \pm 0.04 *$ & $2.72 \pm 0.06$ & NS & $2.86 \pm 0.09$ & $2.74 \pm 0.09$ & NS \\
\hline RRI LF:HF & $0.93 \pm 0.12 *$ & $17.54 \pm 1.66$ & $<0.001$ & $0.45 \pm 0.06$ & $17.65 \pm 2.41$ & $<0.001$ \\
\hline RRI nLF (\%) & $37.2 \pm 1.8 *$ & $89.4 \pm 0.8$ & $<0.001$ & $27.2 \pm 2.5$ & $90.4 \pm 1.1$ & $<0.001$ \\
\hline RRI nHF (\%) & $61.0 \pm 1.8 \dagger$ & $10.0 \pm 0.8$ & $<0.001$ & $71.5 \pm 2.5$ & $8.9 \pm 1.0$ & $<0.001$ \\
\hline \multicolumn{7}{|l|}{ SBP variability } \\
\hline Log SBP LF (log mmHg $\left.{ }^{2}\right)$ & $0.42 \pm 0.04$ & $1.23 \pm 0.03 \dagger$ & $<0.001$ & $0.28 \pm 0.06$ & $1.03 \pm 0.28$ & $<0.001$ \\
\hline Log SBP HF $\left(\log \mathrm{mmHg}^{2}\right)$ & $0.14 \pm 0.03$ & $0.04 \pm 0.04$ & 0.009 & $0.04 \pm 0.06$ & $0.05 \pm 0.07$ & NS \\
\hline
\end{tabular}

Data are mean \pm SEM

${ }^{\mathrm{a}} 15$ breaths per minute; ${ }^{\mathrm{b}}$ Six breaths per minute

${ }^{*} p<0.05, \dagger p<0.005$ between groups

HF, high-frequency; LF, low-frequency; nHF, normalised HF; nLF, normalised LF; RMSSD, root mean square of the differences of successive RR intervals; RRI, the time interval between two consecutive R peaks of the ECG

diabetes. Conversely, participants with definite denervation due to a heart transplant showed very low levels of resting BRS during controlled breathing at normal rate, which did not increase with slow breathing. Active standing reduced all measures of BRS to a similar extent in diabetic and control participants (Table 4). The different methods showed a high level of agreement (Cronbach's alpha or intraclass correlation coefficient $=0.929$ ).

Table 4 The effect of breathing rate and posture on the different BRS variables in healthy control participants, patients with type 1 diabetes and surgically denervated patients

\begin{tabular}{|c|c|c|c|c|c|c|c|c|}
\hline \multirow{2}{*}{$\begin{array}{l}\text { Effect per group } \\
\text { Breathing rate }^{\mathrm{a}}\end{array}$} & \multicolumn{2}{|c|}{$\mathrm{BRS}+/+(\mathrm{ms} / \mathrm{mmHg})$} & \multicolumn{2}{|c|}{ BRS-/- (ms/mmHg) } & \multicolumn{2}{|c|}{ Alpha LF-BRS (ms/mmHg) } & \multicolumn{2}{|c|}{ TF-BRS (ms/mmHg) } \\
\hline & $\begin{array}{l}\text { Controlled } \\
\text { breathing }\end{array}$ & $\begin{array}{l}\text { Deep- } \\
\text { breathing }\end{array}$ & $\begin{array}{l}\text { Controlled } \\
\text { breathing }\end{array}$ & $\begin{array}{l}\text { Deep- } \\
\text { breathing }\end{array}$ & $\begin{array}{l}\text { Controlled } \\
\text { breathing }\end{array}$ & $\begin{array}{l}\text { Deep- } \\
\text { breathing }\end{array}$ & $\begin{array}{l}\text { Controlled } \\
\text { breathing }\end{array}$ & $\begin{array}{l}\text { Deep- } \\
\text { breathing }\end{array}$ \\
\hline Control $(n=36)$ & $27.4 \pm 3.8$ & $33.9 \pm 4.8$ & $22.6 \pm 2.5$ & $19.5 \pm 1.7$ & $14.1 \pm 1.5$ & $32.5 \pm 3.8 *$ & $13.5 \pm 1.4$ & $28.9 \pm 3.1 *$ \\
\hline $\begin{array}{l}\text { Type } 1 \text { diabetes } \\
(n=116)\end{array}$ & $15.8 \pm 0.6 \dagger$ & $30.6 \pm 1.8 *$ & $15.7 \pm 0.8 \dagger$ & $17.8 \pm 0.7$ & $12.6 \pm 0.7$ & $22.4 \pm 1.0 * \dagger$ & $12.0 \pm 0.7$ & $20.7 \pm 0.9 * \dagger$ \\
\hline $\begin{array}{l}\text { Surgically } \\
\text { denervated }(n=12)\end{array}$ & $1.0 \pm 0.3$ & $0.8 \pm 0.2$ & $0.9 \pm 0.2$ & $1.0 \pm 0.2$ & $0.3 \pm 0.2$ & $0.7 \pm 0.1$ & $0.9 \pm 0.1$ & $1.1 \pm 0.2$ \\
\hline Posture ${ }^{d}$ & Supine & Standing & Supine & Standing & Supine & Standing & Supine & Standing \\
\hline Control $(n=36)$ & $26.8 \pm 3.7$ & $11.7 \pm 1.1$ & $22.9 \pm 1.8$ & $9.8 \pm 0.9$ & $19.0 \pm 1.9$ & $9.9 \pm 0.6$ & $18.2 \pm 1.7$ & $9.1 \pm 0.6$ \\
\hline $\begin{array}{l}\text { Type } 1 \text { diabetes } \\
(n=116)\end{array}$ & $19.6 \pm 1.1$ & $8.3 \pm 0.3$ & $18.4 \pm 0.7$ & $7.4 \pm 0.3$ & $13.0 \pm 0.7$ & $7.6 \pm 0.3$ & $12.4 \pm 0.6$ & $6.8 \pm 0.3$ \\
\hline
\end{tabular}

Data are \pm SEM

${ }^{a}$ All data supine; all BRS values in the first two groups were significantly higher $(p<0.001)$ than those in the third group

${ }^{\mathrm{b}} 15$ breaths per minute; ${ }^{\mathrm{c}} \mathrm{Six}$ breaths per minute

${ }^{\mathrm{d}}$ All data on spontaneous breathing; all comparisons between controls and diabetic or between supine and standing were significant at least for $p<$ 0.005

${ }^{*} p<0.005$ for difference within groups (effect of breathing rate), $\dagger p<0.005$ for difference between the first two groups

LF, low-frequency 


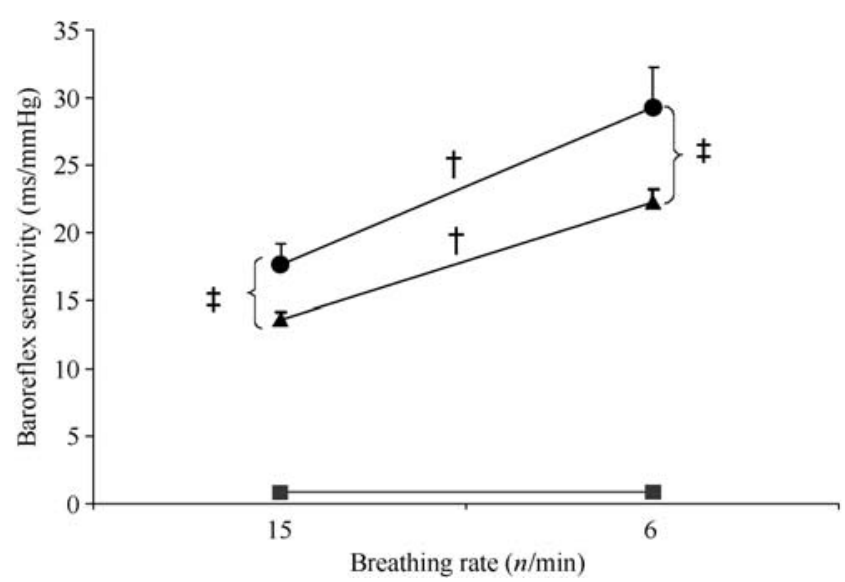

Fig. 1 The effect of breathing rate on the average BRS in participants with normal innervation (healthy control participants; black circles), patients with type 1 diabetes (black triangles) and surgically denervated (heart-transplanted) patients (black squares; difference was NS). $\dagger p<0.005$ for difference within groups, $₫ p<0.005$ for difference between groups. The was no significant difference between the baroflex sensitivity for surgically denervated subjects

\section{Discussion}

Main findings In the present study, we demonstrated a marked reduction of the spontaneous BRS in patients with type 1 diabetes, even in the absence of any clinically detectable diabetic complications. The reduction in BRS co-segregated with signs of sympathetic predominance. Nevertheless, the diabetic participants were able to increase BRS in response to slow deep-breathing, an intervention capable of inducing an increase in BRS in healthy control participants. The opposite intervention, active standing, induced a similar marked reduction in both groups. In contrast, in patients with a denervated heart, BRS did not increase after slow breathing, suggesting that the abnormalities seen in the patients with type 1 diabetes could at least to some extent be considered functional. This observation could have important implications for our understanding of the natural history of autonomic neuropathy.

Autonomic abnormalities in type 1 diabetes Previous studies in more heterogeneous groups of patients with type 1 diabetes have demonstrated a reduction in various indices of HRV [13], suggestive of a reduction in vagal activity. The present study also confirms those previous findings of reduced vagal activity and relative increase in sympathetic activity. Essentially, these previous findings were replicated here by: (1) showing a lower global HRV (assessed by the $\mathrm{SD}$ of RR interval); (2) the relative increase in the lowfrequency components; (3) the relative and absolute reduction in the high-frequency components of $\mathrm{HRV}$; and (4) the higher low-frequency:high-frequency ratio, as assessed by spectral analysis. It is of note that reduced BRS was found to be a sensitive marker of autonomic cardiovascular dysregulation in a population of type 1 diabetic patients with a wide range of age and diabetes duration [10] and that such a reduction in BRS has furthermore been repeatedly reported by different studies in type 1 and type 2 diabetic patients [9, 11, 12, 15]. Our findings also support these previous data, but, importantly, do so even in the absence of clinical complications or in the absence of alterations in the autonomic function tests. As a consequence of impaired BRS, blood pressure changes are not buffered by the heart rate in the low-frequency region.

In our study, a significant inverse correlation was observed between blood pressure indices and BRS variables (data not shown). Importantly, evidence now accumulating suggests that impaired BRS may precede development of hypertension [40-42]. We have previously demonstrated that even in the absence of diabetic kidney disease, type 1 diabetes is associated with isolated systolic hypertension and a prematurely increasing pulse pressure, suggestive of accelerated arterial stiffening [43]. It can be hypothesised that autonomic dysfunction may be the reason for the higher blood pressure seen in our earlier study. Notably, in the present study, the patients with type 1 diabetes also had higher SBP and DBP than the healthy control participants, albeit within the upper normal range.

Significance of BRS alteration: organic or functional? As confirmed in the present study, diabetic microvascular complications are rare during the first decade of diabetes [44-46]. Due to the selection of a cohort with a disease duration of $<10$ years, our study was designed to evaluate autonomic function of patients in the window before diabetic late complications become evident. Although the cross-sectional design limits conclusions about mechanisms and temporal relations, it may be that autonomic dysfunction precedes other diabetic complications, possibly even playing a role in their pathogenesis. However, here, for the first time as far as we are aware, we have shown that the BRS can be increased towards normal values simply by slowing the breathing rate to six breaths per minute in patients with type 1 diabetes. The magnitude of the increase was maximal in the healthy control participants, slightly reduced in the diabetic patients and totally absent in participants with denervated hearts. Thus, this ability to increase BRS suggests that the autonomic nervous system may still be able to react to a simple intervention in a favourable way in patients with type 1 diabetes. This finding is complemented by the other observation that the opposite intervention, active standing, reduced the BRS to a similar extent in control and diabetic participants (Table 4), indicating that the cardiovascular regulation is still operative, when appropriately stimulated. 
All these findings suggest that, in patients with type 1 diabetes, the changes are to a large extent the result of a functional autonomic involvement. The fact that the autonomic involvement has an important functional component does not, however, preclude its clinical importance, as the prognostic value of a reduced BRS has already been established in a number of conditions associated with functional alterations in the autonomic nervous system. Notably, in heart failure and after myocardial infarction, interventions like physical training have generated rather strong evidence of a reversal of autonomic abnormalities $[24,25]$. Recent studies also seem to confirm that autonomic abnormalities can also be favourably influenced by physical exercise in patients with type 2 diabetes [47, 48]. On the other hand, our findings are not in contrast with the development of progressive autonomic neuropathy at a later stage. Increased sympathetic activity can cause activation of the renin-angiotensin system, decrease arterial compliance and increase water and sodium retention in the kidneys, all conditions that lead to elevated blood pressure and may contribute to tissue hypoxaemia and the development of autonomic neuropathy. Accordingly, strategies to prevent sympathetic over-activation could also be protective against the development of clinically evident autonomic neuropathy.

At variance with other reports $[49,50]$, we did not find any correlation between $\mathrm{HbA}_{\mathrm{lc}}$ and autonomic indices in our patients with type 1 diabetes. This could be due to a number of facts, including, first of all, different patient selection, fairly good metabolic control, the mild autonomic involvement (with absence of symptoms) and the possible inherent lack of correlation between a measure of relatively short-term metabolic control and a dysfunction that may take years to develop. We could not find any correlations between microvascular complications and BRS, probably because of the absence of such abnormalities in most of the studied patients (Table 1). Such a relationship might be found when studying more compromised patients.

Study limitations The conclusions of this study are based on observations in a group of type 1 diabetic patients with only mild autonomic involvement. The results could therefore be different in patients with more advanced disease, where a large proportion of organic neural lesions would be expected. It is thus likely that in such patients the BRS response with slow breathing might be more similar to that seen in patients with surgically denervated heart. Further studies (currently in progress) will clarify this point. Nevertheless, our study does provide a simple test to evaluate the extent of organic involvement and to track early autonomic neuropathy in patients unable to increase BRS in response to slow breathing.

Conclusions Our observations suggest that increased sympathetic activity and reduced BRS occur early in the course of type 1 diabetes. However, the demonstration that patients with diabetes can increase (or decrease) their BRS in response to a simple physiological stimulus suggests that the abnormality is largely functional, at least at an early stage of the disease. Thus, the present findings may suggest a new way to track and potentially prevent cardiovascular complications in patients with type 1 diabetes.

Acknowledgements This study was supported by the Folkhälsan Research Foundation, the Wilhelm and Else Stockmann Foundation, the Finnish Medical Society (Finska Läkaresällskapet), the Waldemar von Frenckell Foundation and a special governmental grant for health sciences research (no. 7301). The skilled technical assistance of the FinnDiane Study Group is gratefully acknowledged. We acknowledge the extensive help provided by T. Kuusela (University of Turku, Finland).

Duality of interest The authors declare that there is no duality of interest associated with this manuscript.

\section{References}

1. Maser RE, Mitchell BD, Vinik AI, Freeman R (2003) The association between cardiovascular autonomic neuropathy and mortality in individuals with diabetes: a meta-analysis. Diabetes Care 26:1895-1901

2. Curtis BM, O'Keefe JH Jr (2002) Autonomic tone as a cardiovascular risk factor: the dangers of chronic fight or flight. Mayo Clin Proc 77:45-54

3. La Rovere MT, Bigger JT Jr, Marcus FI, Mortara A, Schwartz PJ (1998) Baroreflex sensitivity and heart-rate variability in prediction of total cardiac mortality after myocardial infarction. ATRAMI (Autonomic Tone and Reflexes After Myocardial Infarction) Investigators. Lancet 351:478-484

4. De Ferrari GM, Sanzo A, Bertoletti A, Specchia G, Vanoli E, Schwartz PJ (2007) Baroreflex sensitivity predicts long-term cardiovascular mortality after myocardial infarction even in patients with preserved left ventricular function. J Am Coll Cardiol 50:2285-2290

5. Mortara A, La Rovere MT, Pinna GD et al (1997) Arterial baroreflex modulation of heart rate in chronic heart failure: clinical and hemodynamic correlates and prognostic implications. Circulation 96:3450-3458

6. La Rovere MT, Pinna GD, Maestri R et al (2003) Short-term heart rate variability strongly predicts sudden cardiac death in chronic heart failure patients. Circulation 107:565-570

7. Mancia G, Parati G, Pomidossi G, Casadei R, Di Rienzo M, Zanchetti A (1986) Arterial baroreflexes and blood pressure and heart rate variabilities in humans. Hypertension 8:147-153

8. Parati G, Frattola A, Omboni S, Mancia G, Di Rienzo M (1996) Analysis of heart rate and blood pressure variability in the assessment of autonomic regulation in arterial hypertension. Clin Sci (Lond) 91(Suppl):129-132

9. Weston PJ, James MA, Panerai R et al (1996) Abnormal baroreceptor-cardiac reflex sensitivity is not detected by conventional tests of autonomic function in patients with insulindependent diabetes mellitus. Clin Sci (Lond) 91:59-64

10. Weston PJ, James MA, Panerai RB, McNally PG, Potter JF, Thurston H (1998) Evidence of defective cardiovascular regulation in insulin-dependent diabetic patients without clinical autonomic dysfunction. Diabetes Res Clin Pract 42:141-148 
11. Lefrandt JD, Hoogenberg K, van Roon AM, Dullaart RP, Gans RO, Smit AJ (1999) Baroreflex sensitivity is depressed in microalbuminuric Type I diabetic patients at rest and during sympathetic manoeuvres. Diabetologia 42:1345-1349

12. Frattola A, Parati G, Gamba P et al (1997) Time and frequency domain estimates of spontaneous baroreflex sensitivity provide early detection of autonomic dysfunction in diabetes mellitus. Diabetologia 40:1470-1475

13. Ziegler D, Laude D, Akila F, Elghozi JL (2001) Time- and frequency-domain estimation of early diabetic cardiovascular autonomic neuropathy. Clin Auton Res 11:369-376

14. Ziegler D, Dannehl K, Volksw D, Muhlen H, Spuler M, Gries FA (1992) Prevalence of cardiovascular autonomic dysfunction assessed by spectral analysis and standard tests of heart-rate variation in newly diagnosed IDDM patients. Diabetes Care 15:908-911

15. Dalla Pozza R, Bechtold S, Bonfig W et al (2007) Impaired shortterm blood pressure regulation and autonomic dysbalance in children with type 1 diabetes mellitus. Diabetologia 50:2417-2423

16. Wheeler T, Watkins PJ (1973) Cardiac denervation in diabetes. BMJ 4:584-586

17. Bernardi L, Gabutti A, Porta C, Spicuzza L (2001) Slow breathing reduces chemoreflex response to hypoxia and hypercapnia, and increases baroreflex sensitivity. J Hypertens 19:2221-2229

18. Bernardi L, Porta C, Spicuzza L et al (2002) Slow breathing increases arterial baroreflex sensitivity in patients with chronic heart failure. Circulation 105:143-145

19. Joseph CN, Porta C, Casucci G et al (2005) Slow breathing improves arterial baroreflex sensitivity and decreases blood pressure in essential hypertension. Hypertension 46:714-718

20. Raupach T, Bahr F, Herrmann P et al (2008) Slow breathing reduces sympathoexcitation in chronic obstructive pulmonary disease. Eur Respir J 32:387-392

21. Goso Y, Asanoi H, Ishise H et al (2001) Respiratory modulation of muscle sympathetic nerve activity in patients with chronic heart failure. Circulation 104:418-423

22. Naughton MT, Floras JS, Rahman MA, Jamal M, Bradley TD (1998) Respiratory correlates of muscle sympathetic nerve activity in heart failure. Clin Sci (Lond) 95:277-285

23. Montano N, Ruscone TG, Porta A, Lombardi F, Pagani M, Malliani A (1994) Power spectrum analysis of heart rate variability to assess the changes in sympathovagal balance during graded orthostatic tilt. Circulation 90:1826-1831

24. Coats AJ, Adamopoulos S, Radaelli A et al (1992) Controlled trial of physical training in chronic heart failure. Exercise performance, hemodynamics, ventilation, and autonomic function. Circulation 85:2119-2131

25. Piepoli MF, Davos C, Francis DP, Coats AJ, ExTraMATCH Collaborative (2004) Exercise training meta-analysis of trials in patients with chronic heart failure (ExTraMATCH). BMJ 328:189

26. Lounamaa R (1993) Mortality in Finnish patients with insulindependent diabetes mellitus. Social Insurance Institution, Finland

27. Bernardi L, Bianchini B, Spadacini G et al (1995) Demonstrable cardiac reinnervation after human heart transplantation by carotid baroreflex modulation of RR interval. Circulation 92:2895-2903

28. Kahn R (1992) Proceedings of a consensus development conference on standardized measures in diabetic neuropathy. Autonomic nervous system testing. Diabetes Care 15:1095-1103

29. Boulton AJ, Vinik AI, Arezzo JC et al (2005) Diabetic neuropathies: a statement by the American Diabetes Association. Diabetes Care 28:956-962

30. Pinna GD, Maestri R, La Rovere MT, Gobbi E, Fanfulla F (2006) Effect of paced breathing on ventilatory and cardiovascular variability parameters during short-term investigations of autonomic function. Am J Physiol Heart Circ Physiol 290:H424-H433
31. Bernardi L, Wdowczyk-Szulc J, Valenti C et al (2000) Effects of controlled breathing, mental activity and mental stress with or without verbalization on heart rate variability. J Am Coll Cardiol 35:1462-1469

32. Daffonchio A, Franzelli C, Radaelli A et al (1995) Sympathectomy and cardiovascular spectral components in conscious normotensive rats. Hypertension 25:1287-1293

33. Laude D, Elghozi JL, Girard A et al (2004) Comparison of various techniques used to estimate spontaneous baroreflex sensitivity (the EuroBaVar study). Am J Physiol Regul Integr Comp Physiol 286: R226-R231

34. Bertinieri G, di Rienzo M, Cavallazzi A, Ferrari AU, Pedotti A, Mancia G (1985) A new approach to analysis of the arterial baroreflex. J Hypertens Suppl 3:S79-S81

35. Pagani M, Somers V, Furlan R et al (1988) Changes in autonomic regulation induced by physical training in mild hypertension. Hypertension 12:600-610

36. Pinna GD, Maestri R (2001) Reliability of transfer function estimates in cardiovascular variability analysis. Med Biol Eng Comput 39:338-347

37. American Diabetes Association (2006) Standards of medical care in diabetes-2006. Diabetes Care 29:S4-S42

38. Bravo G, Potvin L (1991) Estimating the reliability of continuous measures with Cronbach's alpha or the intraclass correlation coefficient: toward the integration of two traditions. J Clin Epidemiol 44:381-390

39. Bland JM, Altman DG (1997) Cronbach's alpha. BMJ 314:572

40. Bristow JD, Honour AJ, Pickering GW, Sleight P, Smyth HS (1969) Diminished baroreflex sensitivity in high blood pressure. Circulation 39:48-54

41. Ducher M, Fauvel JP, Cerutti C (2006) Risk profile in hypertension genesis: A five-year follow-up study. Am J Hypertens 19:775-780

42. Hesse C, Charkoudian N, Liu Z, Joyner MJ, Eisenach JH (2007) Baroreflex sensitivity inversely correlates with ambulatory blood pressure in healthy normotensive humans. Hypertension 50:41-46

43. Ronnback M, Fagerudd J, Forsblom C et al (2004) Altered agerelated blood pressure pattern in type 1 diabetes. Circulation 110:1076-1082

44. Andersen AR, Christiansen JS, Andersen JK, Kreiner S, Deckert T (1983) Diabetic nephropathy in Type 1 (insulin-dependent) diabetes: an epidemiological study. Diabetologia 25:496-501

45. Klein R, Klein BE, Moss SE, Davis MD, DeMets DL (1984) The Wisconsin epidemiologic study of diabetic retinopathy. II. Prevalence and risk of diabetic retinopathy when age at diagnosis is less than 30 years. Arch Ophthalmol 102:520-526

46. Walsh MG, Zgibor J, Borch-Johnsen K, Orchard TJ (2004) A multinational comparison of complications assessment in type 1 diabetes: The DiaMond substudy of complications (DiaComp) level 2. Diabetes Care 27:1610-1617

47. Loimaala A, Huikuri HV, Koobi T, Rinne M, Nenonen A, Vuori I (2003) Exercise training improves baroreflex sensitivity in type 2 diabetes. Diabetes 52:1837-1842

48. Figueroa A, Baynard T, Fernhall B, Carhart R, Kanaley JA (2007) Endurance training improves post-exercise cardiac autonomic modulation in obese women with and without type 2 diabetes. Eur J Appl Physiol 100:437-444

49. The Diabetes Control and Complications Trial Research Group (1998) The effect of intensive diabetes therapy on measures of autonomic nervous system function in the Diabetes Control and Complications Trial (DCCT). Diabetologia 41:416-423

50. Ziegler D, Weise F, Langen KJ et al (1998) Effect of glycaemic control on myocardial sympathetic innervation assessed by [123I] metaiodobenzylguanidine scintigraphy: a 4-year prospective study in IDDM patients. Diabetologia 41:443-451 